\title{
Long-Term Follow-up of a Homozygous Familial Hypercholesterolemia Child with Progressive Aortic Stenosis and Coronary Atherosclerosis
}

Gaojun Cai ( $\sim$ cgj982@126.com )

Wujin hospital affiliated to Jiangsu University https://orcid.org/0000-0003-4250-180X

Long Jiang

Second affiliated hospital of NanChang Univerrsity

Ya Yang

Capital Medical University Affiliated Anzhen Hospital

Liyuan Sun

Capital Medical University Affiliated Anzhen Hospital

Xu Wang

Capital Medical University Affiliated Anzhen Hospital

Yujie Zhou

Capital Medical University Affiliated Anzhen Hospital

Lvya Wang

Capital Medical University Affiliated Anzhen Hospital

\section{Short report}

Keywords: hypercholesterolemia, familial hypercholesterolemia, autosomal dominant, genetic testing

Posted Date: June 18th, 2020

DOl: https://doi.org/10.21203/rs.3.rs-35528/v1

License: (c) (1) This work is licensed under a Creative Commons Attribution 4.0 International License. Read Full License 


\section{Abstract}

Familial hypercholesterolemia $(\mathrm{FH})$ is a severe autosomal-dominant disorder. We reported a case who firstly admitted to our institution for obvious cutaneous and tendinous xanthomas and high low-density lipoprotein cholesterol when he was 3.7 year old in 2005. DNA sequencing detected the homozygous mutation in LDLR exon9 c.1187-10G>A, a 3' splice acceptor mutation in poly-pyrimidine tract of intron 8. During the long-term follow-up, progressive aortic stenosis and coronary atherosclerosis was found, although given the lipid-lowing drugs. HoFH with c.1187-10G>A mutation in LDLR gene might lead to severe damage in cardiovascular system and unsatisfactory response to conventional lipid-lowing drugs. Other aggressive treatments should be used in HoFH patients with this mutation as early as possible.

\section{Introduction}

Familial hypercholesterolemia $(\mathrm{FH})$ is a severe autosomal-dominant disorder, which is characterized by elevated serum low-density lipoprotein cholesterol (LDL-C) levels, cutaneous and/or tendinous xanthomas, corneal arcus and premature coronary artery disease (pCAD). It is mainly caused by genetic mutations in several genes including LDL receptor (LDLR), apolipoprotein $B$, proprotein convertase subtilisin/kexin9 (PCKS9) and LDLRAP1 genes. ${ }^{1}$ Recent study showed a prevalence of $1 / 300$ for HeFH, and $1 / 160,000-1 / 300,000$ for HoFH in general population. ${ }^{2}$

The harm of $\mathrm{FH}$ is mainly due to the extreme increased LDL-C levels damaging vascular endothelium. If the elevated plasma LDL-C levels were not controlled effectively, it will cause progressive aortic valve stenosis and coronary atherosclerosis. Most of HoFH patients will die before the third decade if untreated. In this report, we reported 13-year follow-up of a HoFH child, who only took oral lipid-lowing drugs and suffered progressive aortic lesions and coronary artery stenosis. This study was approved by the AnZhen Hospital research ethics committee, and an informed consent form was signed by his mother.

\section{Case Report}

In 2005, a 3.7-year-old boy from Henan, China, was first admitted to our institution for obvious cutaneous and tendinous xanthomas. When he was one-year old, he was admitted to another hospital for xanthomas and found hypercholesterolemia. After one year later, he was given simvastatin $(5 \mathrm{mg} / \mathrm{qn})$ to reduce the cholesterol levels. The first- and second- degree relatives had no xanthomas and familial history of pCAD. Physical examination found multiple xanthomas of different sizes distributed in wrists, elbows, ankles, knees, heel and hip (Fig 1). Lipid profile examination showed that total cholesterol (TC) and LDL-C levels were $592 \mathrm{mg} / \mathrm{dl}(15.38 \mathrm{mmol} / \mathrm{l})$ and $535 \mathrm{mg} / \mathrm{dl}(13.90 \mathrm{mmol} / \mathrm{l})$, respectively. Echocardiogram found mild mitral insufficiency and enlargement of left ventricle. The carotid ultrasound suggested that the membrane of total carotid artery thickened on both sides. Because his father did not cooperate with the examination, only his mother accepted biochemical examination. The results showed that TC and LDL-C levels in his mother were $333 \mathrm{mg} / \mathrm{dl}(8.66 \mathrm{mmol} / \mathrm{l})$ and $253 \mathrm{mg} / \mathrm{dl}(6.57 \mathrm{mmol} / \mathrm{l})$, respectively. According to the Dutch Lipid Clinic Network Criteria (DNLC), ${ }^{3}$ the child was diagnosed 
clinically with HoFH. Subsequently, to identify the type of mutation, whole exome sequencing was carried out. The methods of DNA extraction and sequencing have been reported in our previous studies. ${ }^{4}$ The homozygous mutation in LDLR exon9 c.1187-10G>A, a 3' splice acceptor mutation in poly-pyrimidine tract of intron 8 , was detected in the child and the heterozygous form was detected in his mother.

Considering the high cost and surgical operation risk, his parents choose oral lipid-lowing drugs to reduce the lipid levels instead of lipid apheresis or liver transplantation. Based on the diatery restriction, ezetimibe ( $5 \mathrm{mg} / \mathrm{qd})$ and probucol $(0.5 \mathrm{mg} / \mathrm{bid})$ were added, and dose of simvastatin was modified from $5 \mathrm{mg} / \mathrm{qn}$ to $10 \mathrm{mg} / \mathrm{qn}$.

After that, his lipid profiles and echocardiography results were followed up (Fig 2, 3). In 2010, biochemical examination showed that TC and LDL-C levels elevated to $777 \mathrm{mg} / \mathrm{dl}(20.17 \mathrm{mmol} / \mathrm{l})$ and $644 \mathrm{mg} / \mathrm{dl}$ ( $16.74 \mathrm{mmol} / \mathrm{l})$, respectively. From then, TC levels fluctuated between 19.48 to $20.73 \mathrm{mmol} / \mathrm{l}$ until 2015 , followed by a mild decline. Interestingly, we found TG and HDL-C levels gradually decreased from 2010 to 2018. In 2010, Echocardiograph showed mild thickening in aortic and mitral valves, and mild regurgitation of aortic valve, mitral and tricuspid valves (Fig 4A). After suffering from one year repeated chest tightness, he was admitted to cardiovascular department in our hospital in 2015. Coronary angiography (CAG) examination was carried out and the results showed that a $90 \%$ stenosis in right coronary artery (RCA) and a 70\% stenosis in the middle of left anterior descending (LAD). Then a stent was implanted in RCA. After that, atorvastatin $(20 \mathrm{mg} / \mathrm{qn})$, ezetimibe $(10 \mathrm{mg} / \mathrm{qd})$ and probucol $(0.5 \mathrm{mg} /$ bid) were used to control cholesterol levels. In 2017, she was admitted to our hospital again for chest pain. Echocardiograph is shown in Fig 4B. Compared to 2010, strong echoes plaque was present and protruded into the aortic root, which leaded to left ventricular outflow tract stenosis. Multiple calcification and thickening were also observed in aortic isthmus, aortic noncoronary cusp valve and mitral valves. CAG showed that a mild restenosis in previous stent was appeared in RCA. A new $80 \%$ stenosis in left circumflex (LCX) artery was observed, although there was no obvious progression of the stenosis in LAD. Unfortunately, we were informed by his mother that he was died in 2018 December because of cardiac sudden death.

\section{Discussion}

Epidemiological data showed that the prevalence of $\mathrm{FH}$ was 0.28 percent in general population and 7.1 percent in patients with myocardial infarction in China. ${ }^{5,6}$ Another study showed a prevalence of 3.5 percent $\mathrm{FH}$ in patients undergoing CAG examination, using genetic diagnosis criteria. ${ }^{7}$ China accounts for more than one fifth of the world's population. There are about 3.8 million potential $\mathrm{FH}$ patients in China. ${ }^{8}$ However, the underdiagnosis and undertreatment was common.

Several diagnostic criteria have been reported to identify FH. Among them, DNLC criteria were the most accepted and commonly used criteria in clinical diagnosis. ${ }^{3}$ According to scores, patients were defined as definite (>8 scores), probable (6-8 scores), or possible (3-5 scores). In 2018, consensus among Chinese experts on screening, diagnosis and treatment of familial hypercholesterolemia was published. ${ }^{9} \mathrm{FH}$ 
should be diagnosed clinically in children with LDL-C $>3.6 \mathrm{mmol} / \mathrm{l}$ before treatment, and the family history of $\mathrm{FH}$ or premature CAD in first-relatives.

Undoubtedly, the above criteria are mainly based on clinical phenotypes to diagnose FH. However, genetic diagnosis is the gold standard for diagnosing $\mathrm{FH}^{10}$ which may reduce the occurrence of misdiagnose. In current case, we firstly reported the homozygous mutation in LDLR exon9 1187-10G>A (IVS8-10G>A), which is a 3 ' splice acceptor mutation in polypyrimidine tract of intron 8 , using DNA Sanger sequencing method in Chinese population. Up to date, 1741 mutations were recorded in LDLR mutation database (http://www.ucl.ac.uk/ldlr/Current/) and most of them were detected only once. LDLR exon9 1187-10G>A mutation was only reported in Canadian, ${ }^{11}$ Pilipinos, ${ }^{12}$ and French. ${ }^{13}$ Mutation of the G-to-A in the -10 position of the splicing acceptor site might create potential aberrant splice sites according to neuralnetwork computed estimation, ${ }^{13}$ which might lead to abnormal expression of LDLR. This might be partly of reason lipid-lowing drugs having limited effect on the reduction of LDL-C. In addition, this case suffered from serious lesion in cardiac valves and coronary artery in childhood, which might be due to this homozygous mutation.

Statins remain the most common lipid-lowing drugs in $\mathrm{FH}$. However, several prospective studies showed that although most patients were on the maximum lipid-lowering therapy, only $11 \%$ had reached the target of LDL-C levels. ${ }^{14}$ In this case, although given statin and other lipid-lowing drugs, TC levels still increased from $15.38 \mathrm{mmol} / \mathrm{l}$ in 2005 to $20.17 \mathrm{mmol} / \mathrm{l}$ in 2010, followed by a mild decrease. This initial elevation of TC levels might be due to the natural process in children. So, we might underestimate lipid levels in children sometimes, which also suggested that monitor lipid changes in FH children is important. Whether or not to screening FH in children is still a controversial topic. If the plasma LDL-C concentration is not controlled efficiently, progressive aortic valve stenosis and calcification and coronary atherosclerosis will occur. We found progressive aortic root stenosis, multiple calcification and thickening in cardiac valves and coronary artery stenosis in this boy.

Early diagnosis and effective treatment are both critical for prevention the cardiovascular events in $\mathrm{FH}$ patients. PCSK9 inhibitors, including Evolocumab and Alirocumab, could attractively decrease the LDL-C levels in FH and statins intolerance and have been approved by FDA and CFDA. ${ }^{15}$ As the human IgG2 monoclonal antibody, PCSK9 inhibitors can block the interaction between PCSK9 and LDLR, decreasing the degradation of LDLR, then increasing the levels of LDLR on the surface of hepatocytes and facilitating the clearance of plasma LDL-C. In recent years, several RCTs and meta-analysis showed that PCSK9 inhibitors reduced LDL-C levels greatly not only in HeFH, but also in HoFH patients. ${ }^{16,17}$ The HAUSER-RCT study, which is the largest randomized, placebo-controlled study with PCSK9 inhibitor being conducted in the pediatric patients aged 10 to 17 years with $\mathrm{HeFH}$, is ongoing and expects to obtain the efficacy and safety data in these patients. ${ }^{18}$ Despite its definitive lipid-lowering effect, the study on the cost-effectiveness of PCSK9 Inhibitor therapy in patients with HeFH revealed that PCSK9 inhibitor use did not meet generally acceptable incremental cost-effectiveness thresholds, according to the prices in 2015, which might hinder the extensive use worldwide, ${ }^{19}$ especially in developing countries, such as in China. 
With the increasing attention to FH and wildly use of PCSK9 inhibitors in China, we hope more and more FH patients will get effective therapy.

For $\mathrm{HoFH}$, the early diagnosis and effective treatment was critical to prevent arteriosclerosis and cardiovascular events. HoFH with c.1187-10G>A mutation in LDLR gene might lead to severe damage in cardiovascular system and unsatisfactory response to conventional lipid-lowing drugs. Other aggressive treatments should be used in HoFH patients with this mutation as early as possible.

\section{Declaration}

Acknowledgments

The authors thank the Beijing Institute of Heart, Lung, and Blood Vessel Diseases for providing experimental technology support. This work was supported by grants from the National Natural Science Foundation of China (No. 81670811, 81671686 and 81700792), Jiangsu Youth Medical Talents Project (QNRC2016310), and the Changzhou Sci\&Tech Program (Grant No. CE20195003). The fund agencies had no role in the study design, data collection and analysis, decision to publish, or preparation of the manuscript.

Competing financial interests

The authors declare no competing financial interests.

\section{References}

1. lacocca MA, Wang J, Sarkar S, et al. Whole-Gene Duplication of PCSK9 as a Novel Genetic Mechanism for Severe Familial Hypercholesterolemia. Can J Cardiol. 2018; 34(10):1316-1324. doi: 10.1016/j.cjca.2018.07.479. [PMID: 30269829]

2. Gidding SS, Champagne MA, de Ferranti SD, et al. The Agenda for Familial Hypercholesterolemia: A Scientific Statement From the American Heart Association. Circulation. 2015; 132(22): 2167-2192. doi: 10.1161/CIR.0000000000000297. [PMID: 26510694]

3. Williams RR. Familial hypercholesterolaemia-report of a second WHO consultation. Geneva: WHO Human Genetics Programme; 1999.

4. Sun LY, Zhang YB, Jiang $L$, et al. Identification of the gene defect responsible for severe hypercholesterolaemia using whole-exome sequencing. Sci Rep. 2015; 5:11380. doi:

10.1038/srep11380. [PMID: 26077743]

5. Shi Z, Yuan B, Zhao D, Taylor AW, Lin J, Watts GF. Familial hypercholesterolemia in China: prevalence and evidence of underdetection and undertreatment in a community population. Int J Cardiol. 2014; 174(3): 834-836. doi: 10.1016/j.ijcard.2014.04.165. [PMID: 24801084]

6. Li S, Zhang Y, Zhu CG, et al. Identification of familial hypercholesterolemia in patients with myocardial infarction: A Chinese cohort study. J Clin Lipidol. 2016; 10(6): 1344-1352. doi: 
10.1016/j.jacl.2016.08.013. [PMID: 27919351]

7. Li JJ, Li S, Zhu CG, et al. Familial hypercholesterolemia phenotype in Chinese patients undergoing coronary angiography. Arterioscler Thromb Vasc Biol. 2017; 37 (3): 570-579. doi:

10.1161/ATVBAHA.116.308456. [PMID: 27932355]

8. Jiang L, Sun LY, Dai YF, Yang SW, Zhang F, Wang LY. The distribution and characteristics of LDL receptor mutations in China: A systematic review. Sci Rep. 2015; 5:17272. doi: 10.1038/srep17272. [PMID: 26608663]

9. Atherosclerosis and Coronary Heart Disease Section of the Chinese Medical Association, Editorial Committee of the Chinese Journal of Cardiology. Consensus among Chinese experts on screening and diagnosis and treatment of familial hypercholesterol. Chin J Cardiol. 2018; 46(2): 99-103. doi: 10.3760/cma.j.issn.0253-3758.2018.02.006 (Article in Chinese)

10. Wang $X$, Jiang L, Sun LY, et al. Genetically confirmed familial hypercholesterolemia in outpatients with hypercholesterolemia. J Geriatr Cardiol. 2018; 15(6):434-440. doi: 10.11909/j.issn.16715411.2018.06.006. [PMID: 30108616]

11. Wang J, Huff E, Janecka L, Hegele RA. Low density lipoprotein receptor (LDLR) gene mutations in Canadian subjects with familial hypercholesterolemia, but not of French descent. Hum Mutat. 2001; 18(4):359. Doi:10.1002/humu.1205. [PMID:11668627]

12. Punzalan FE, Sy RG, Santos RS, et al. Low density lipoprotein-receptor (LDL-R) gene mutations among Filipinos with familial hypercholesterolemia. J Atheroscler Thromb. 2005; 12(5):276-283. [PMID: 16205024]

13. Amsellem S, Briffaut D, Carrié A, et al. Intronic mutations outside of Alu-repeat-rich domains of the LDL receptor gene are a cause of familial hypercholesterolemia. Hum Genet. 2002; 111(6):501-510. DOI: 10.1007/s00439-002-0813-4. [PMID: 12436241]

14. Perez de Isla L, Alonso R, Watts GF, et al. Attainment of LDL-cholesterol treatments goals in patients with familial hypercholesterolemia. 5-year SAFEHEART registry follow-up. J Am Coll Cardiol. 2016; 67:1278-1285. doi: 10.1016/j.jacc.2016.01.008. [PMID: 26988947]

15. Teramoto T, Kobayashi M, Tasaki H, et al. Efficacy and safety of Alirocumab in Japanese patients with heterozygous familial hypercholesterolemia or at high cardiovascular risk with hypercholesterolemia not adequately controlled with statins-ODYSSEY JAPAN randomized controlled trial. Circ J. 2016; 80(9):1980-1987. doi: 10.1253/circj.CJ-16-0387. [PMID: 27452202]

16. Raal FJ, Honarpour N, Blom DJ, et al. Inhibition of PCSK9 with evolocumab in homozygous familial hypercholesterolaemia (TESLA PartB): a randomised, double-blind, placebo-controlled trial. Lancet. 2015; 385(9965): 341-350. doi: 10.1016/S0140-6736(14)61374-X. [PMID: 25282520]

17. Dian LJ, Gao Y, Zhang YM, Chu M, Yao J, Xu D. Therapeutic efficacy and safety of PCSK9monoclonal antibodies on familial hypercholesterolemia and statin-intolerant patients: A metaanalysis of 15 randomized controlled trials. Sci Rep. 2017; 7(1): 238. doi: 10.1038/s41598-01700316-3. [PMID: 28331223] 
18. Gaudet D, Langslet G, Gidding SS, et al. Efficacy, safety, and tolerability of evolocumab in pediatric patients with heterozygous familial hypercholesterolemia: Rationale and design of the HAUSER-RCT study. J Clin Lipidol. 2018; 12(5):1199-1207. doi: 10.1016/j.jacl.2018.05.007. [PMID: 30318065]

19. Kazi DS, Moran AE, Coxson PG, et al. Cost-effectiveness of PCSK9 Inhibitor Therapy in Patients With Heterozygous Familial Hypercholesterolemia or Atherosclerotic Cardiovascular Disease. JAMA. 2016; 316(7):743-753. doi: 10.1001/jama.2016.11004. [PMID: 27533159]

\section{Figures}

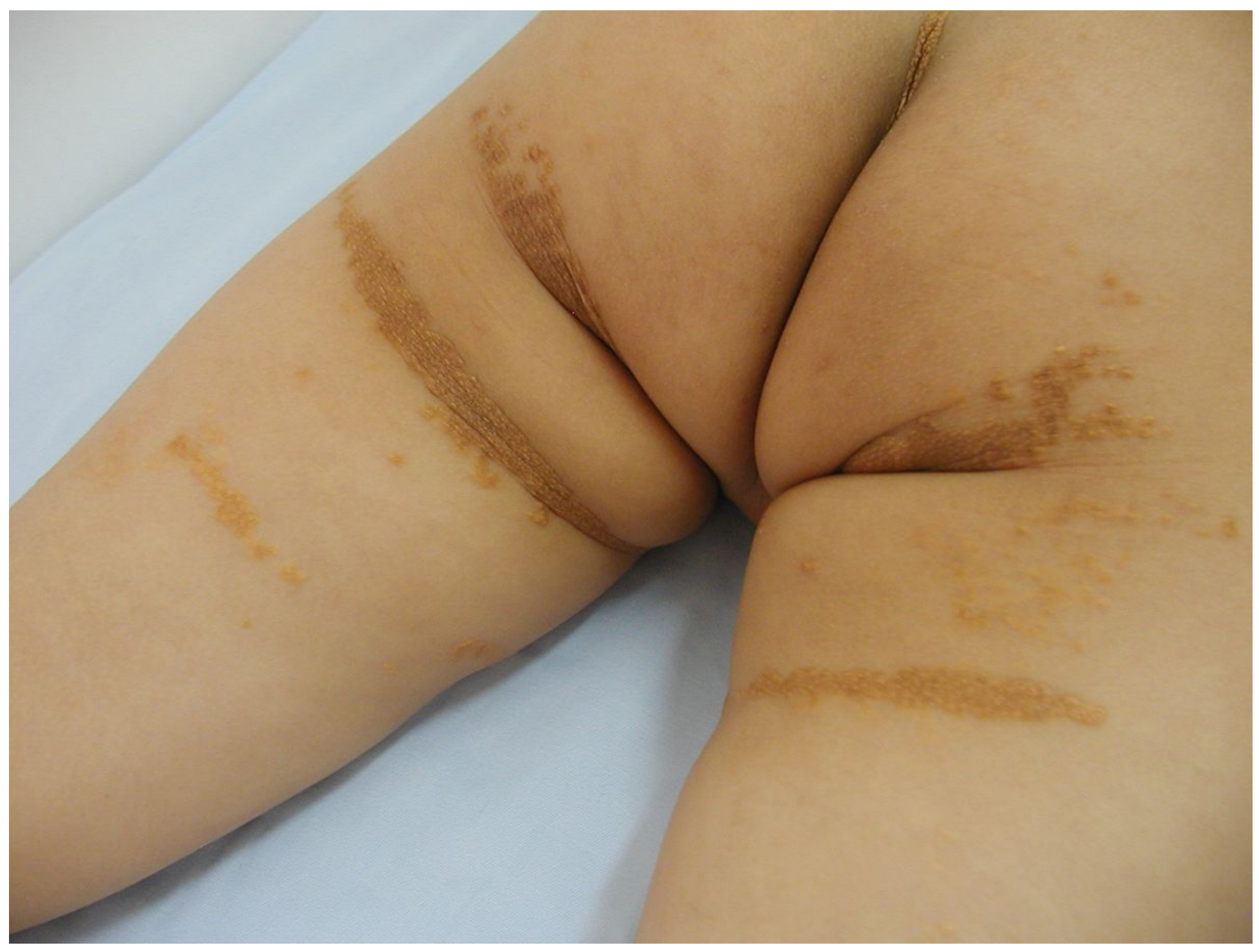

Figure 1

Multiple xanthomas A. In hip 


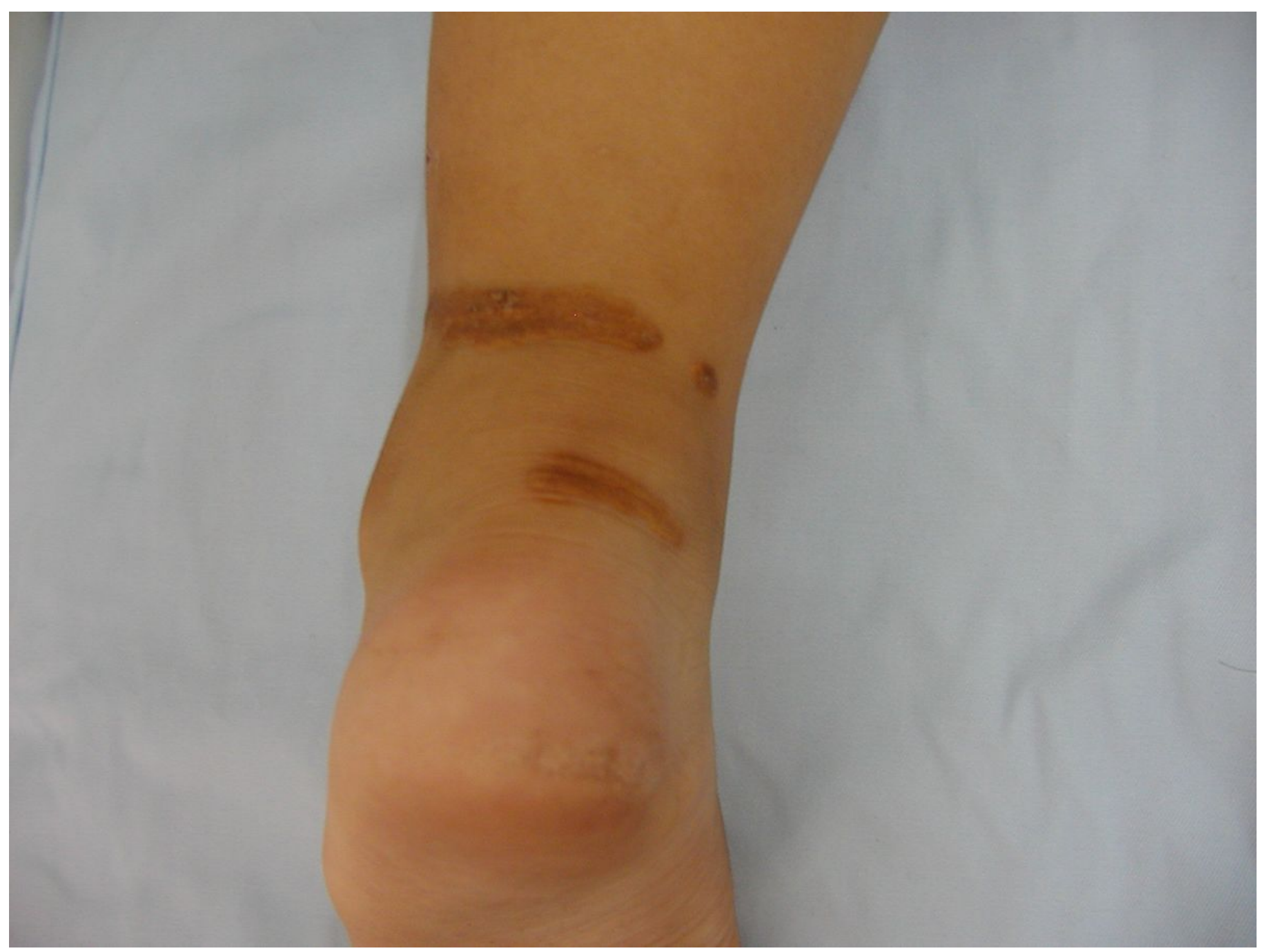

Figure 2

Multiple xanthomas B. In heel 


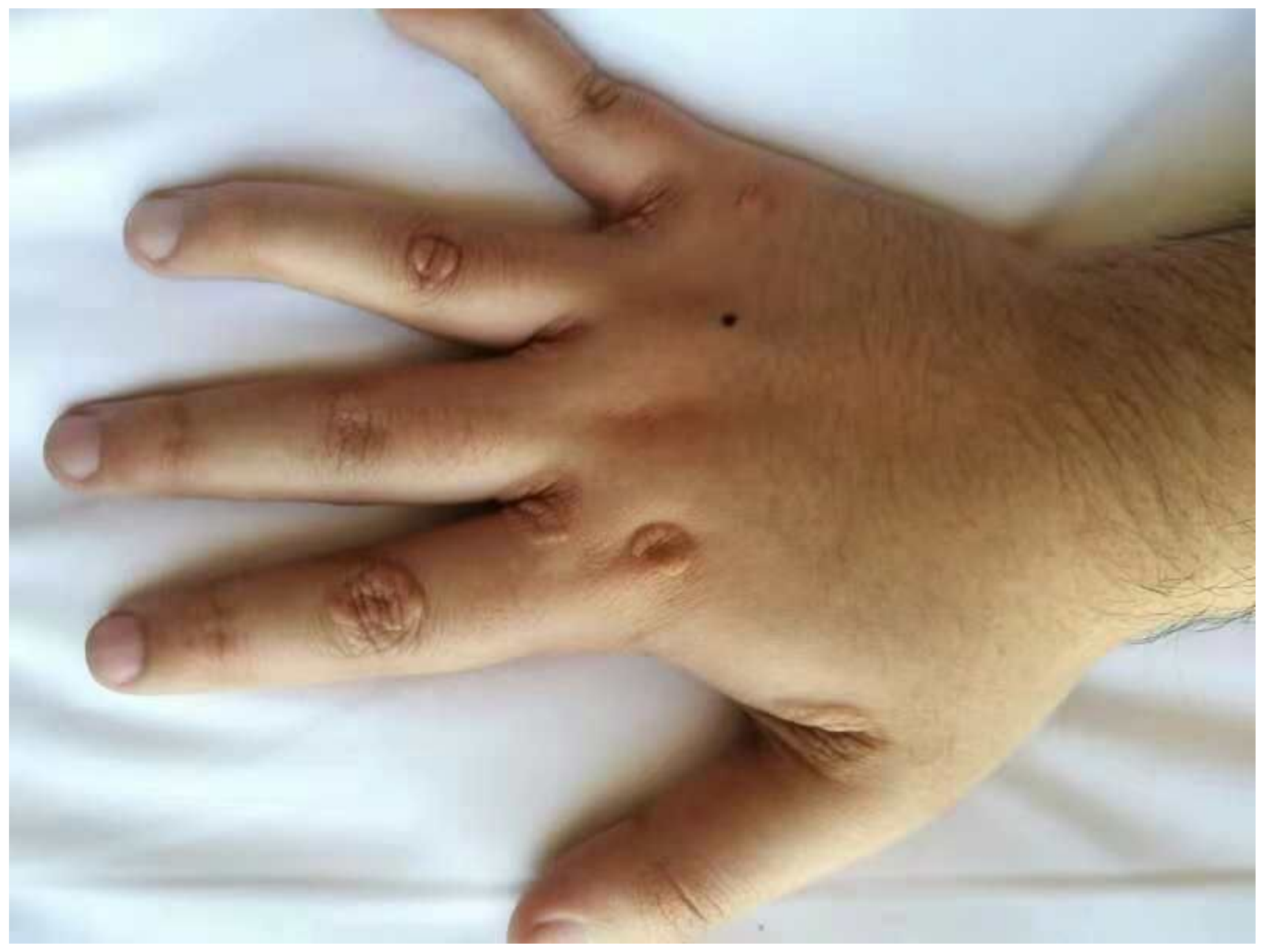

Figure 3

Multiple xanthomas C. In finger joint 


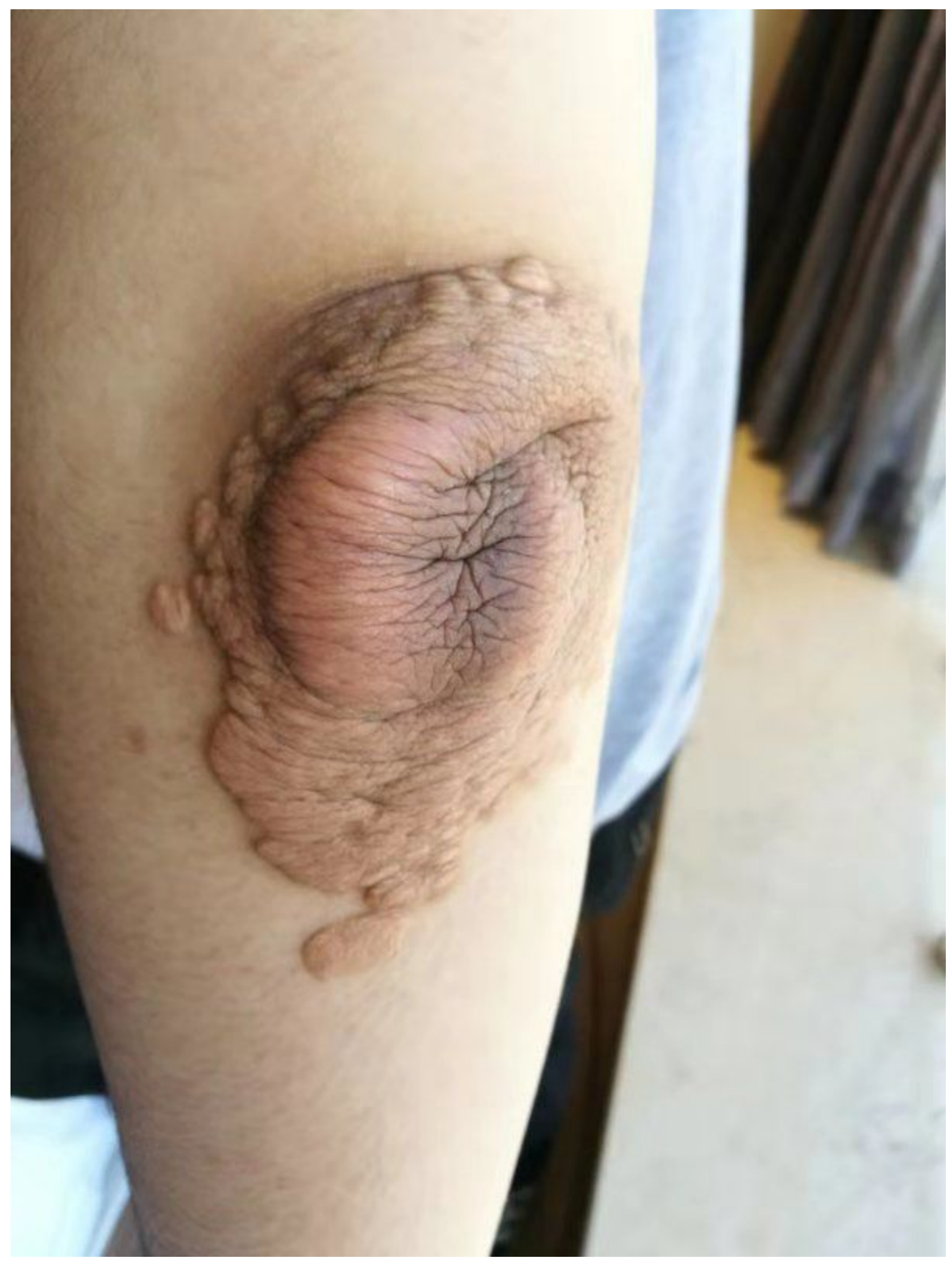

Figure 4

Multiple xanthomas D. In elbow 


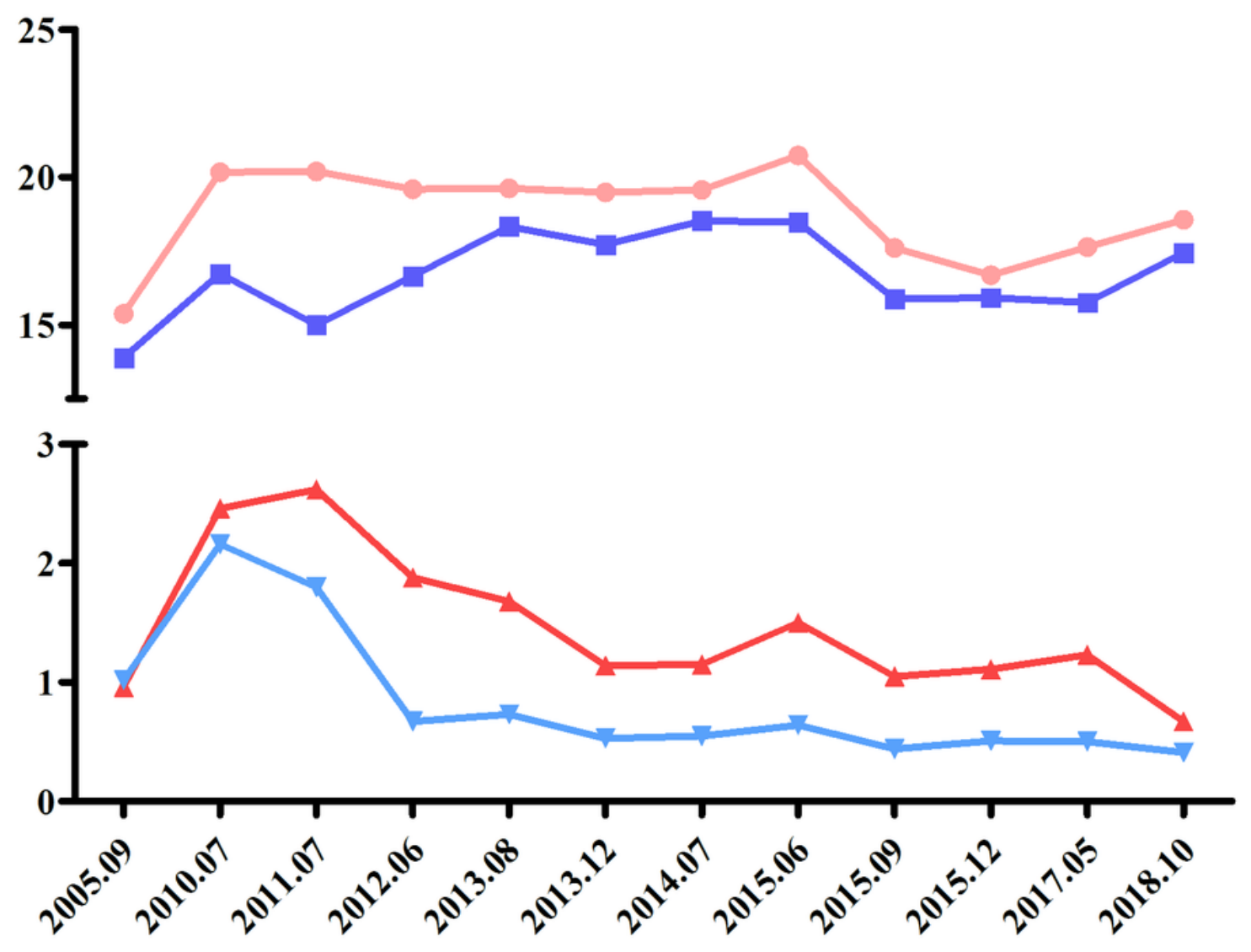

Figure 5

Lipid profiles from 2005 to 2018 TC, total cholesterol; TG, triglyceride; HDL-C, high-density lipoprotein cholesterol; LDL-C, low-density lipoprotein cholesterol 


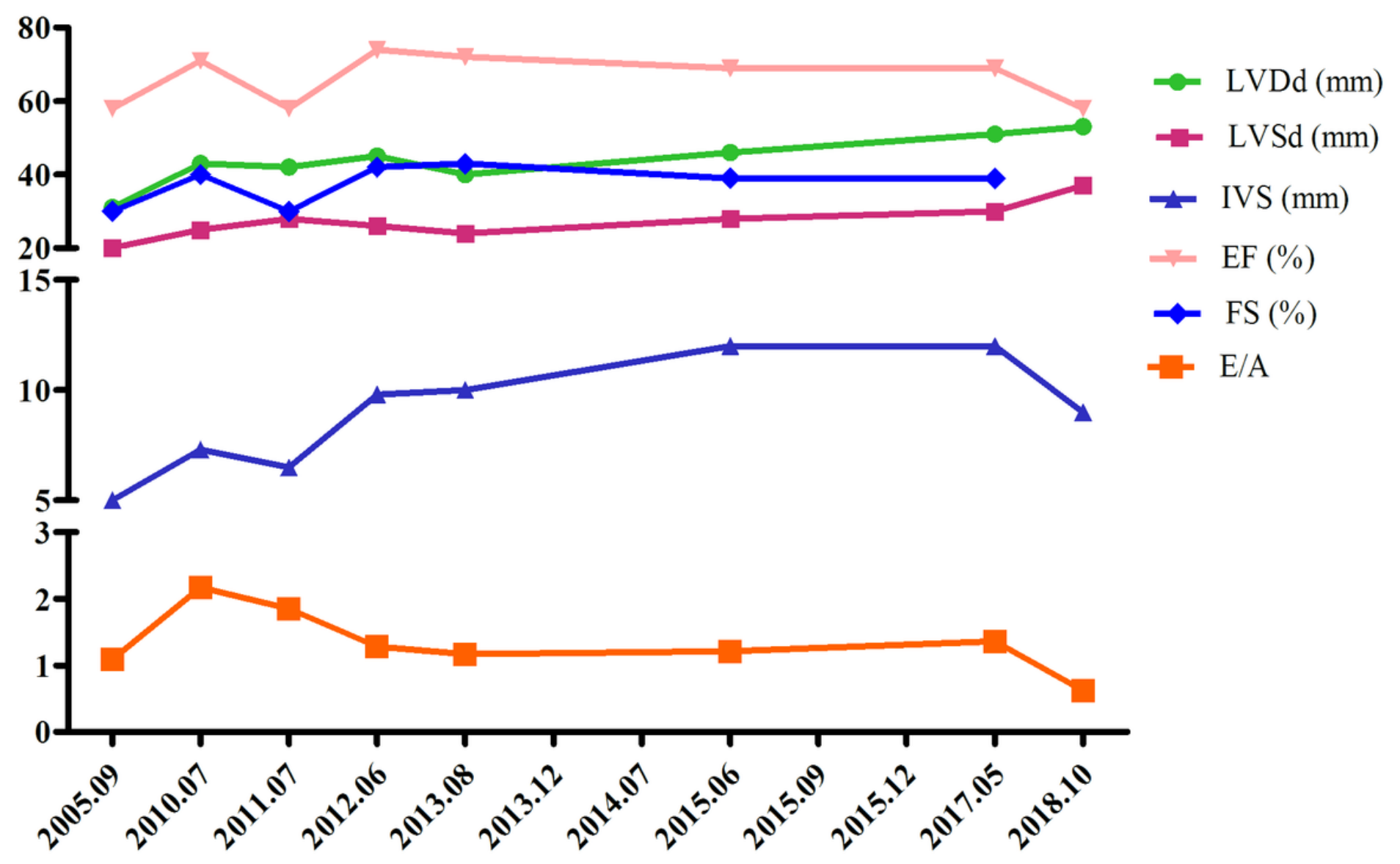

Figure 6

Echocardiography results from 2005 to 2018 LVDd: left ventricle end diastolic diameter; LVSd: left ventricle end systolic diameter; IVS: interventricular septum; EF: ejection fraction; FS: fractional shortening; E/A: ratio of $E$ to $A$ peak. 


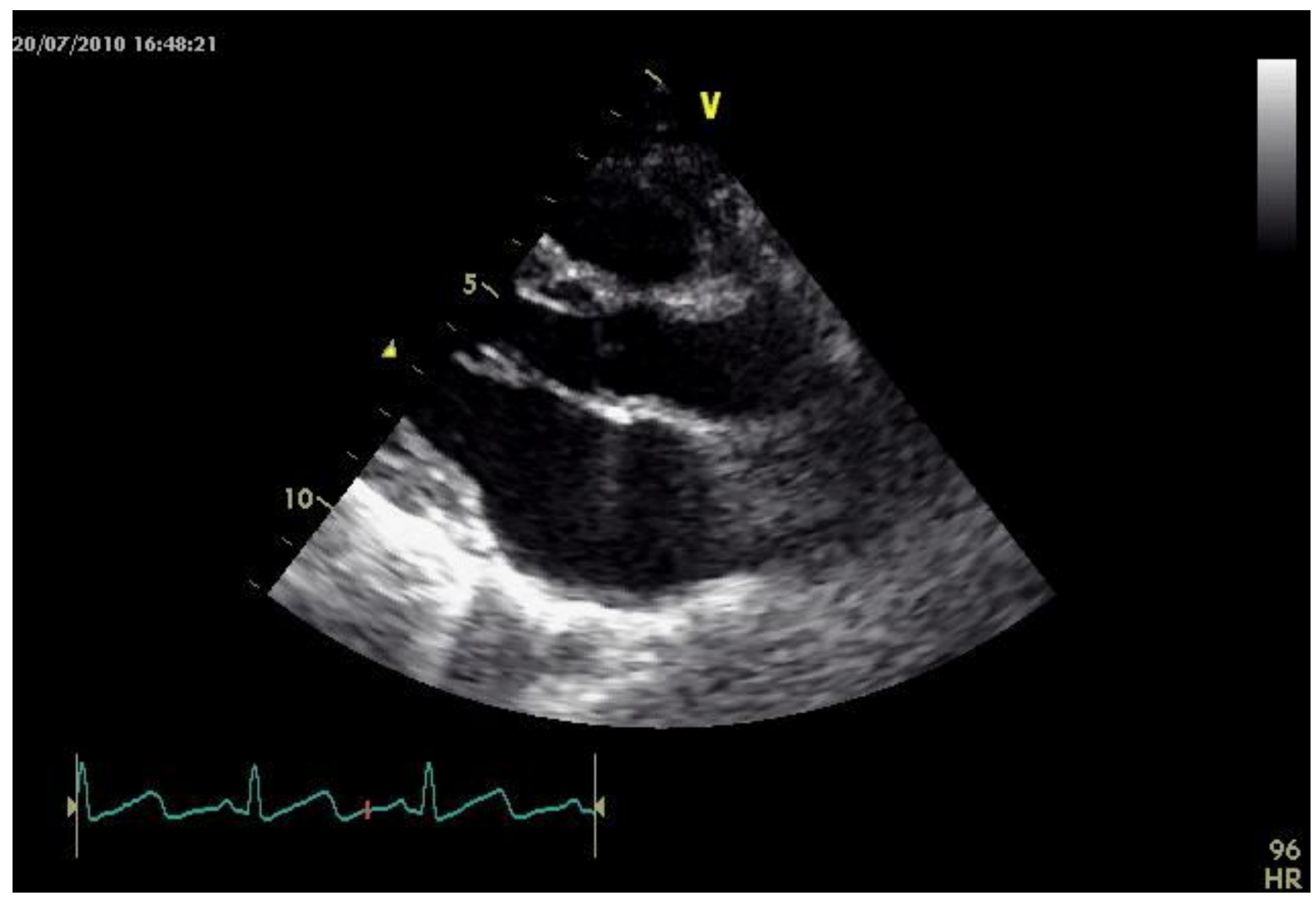

Figure 7

Echocardiography showing progressive valve lesions A, Long axis section of the left heart in 2010

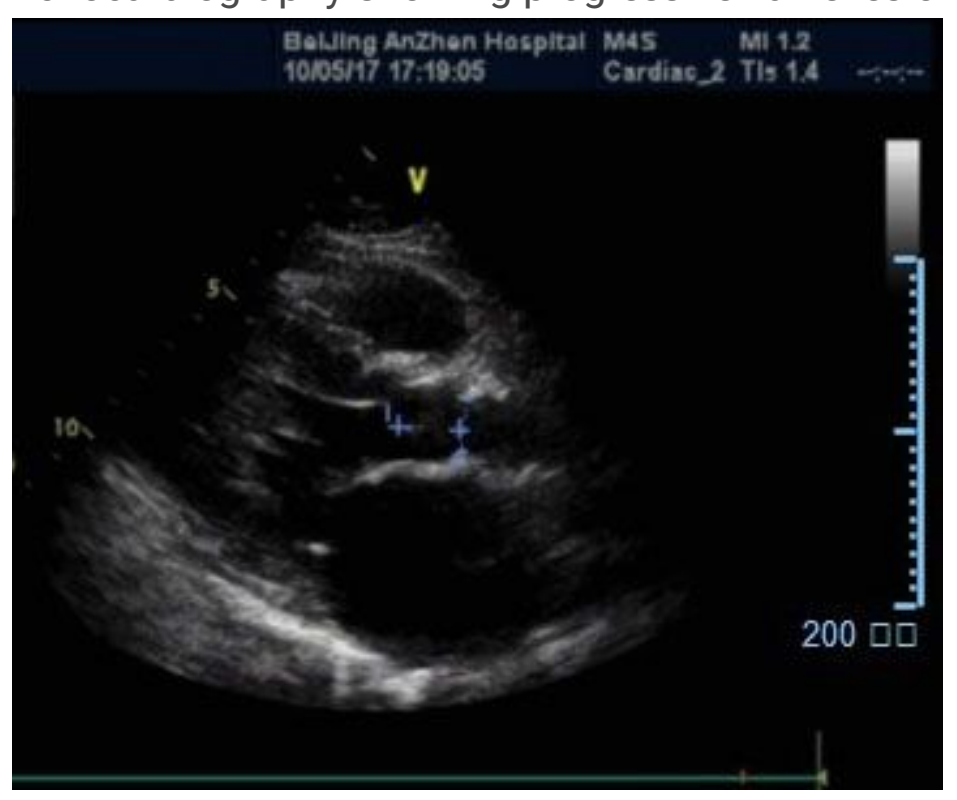

Figure 8

Echocardiography showing progressive valve lesions B, Long axis section of the left heart in 2017 